\title{
Диалог и «чужое слово» как художественные приемы в романе Мигелья де Унамуно «Туман»
}

\author{
Vladimer LUARSABISHVILI \\ Ilia State University (Georgia) \\ tato_luarsabishvili@iliauni.edu.ge
}

Recibido: Diciembre de 2011

Aceptado: Febrero de 2012

\section{Резюме}

В настоящей статье исследуются художественные приемы (диалог и «чужое слово»), которые использует Унамуно как инструменты для построения художественного текста, цель которого заключается в самопознании личности автора. Наше исследование основано на методологиях, которые использовали М.М. Бахтин (на примере романов Достоевского) и Ю.М. Лотман (при анализе художественного текста в целом).

Ключевые слова:Унамуно, Достоевский, Бахтин, Лотман, диалогизм, «чужое сово».

\section{Resumen}

\section{Diálogo y "palabra ajena" en la novela Niebla de Unamuno}

Este artículo analiza las técnicas narrativas de la novela Niebla de Unamuno. El análisis parte de dos métodos: el empleado por M. Baxtin para el estudio de las novelas de F. Dostoevskij; y el que utiliza Lotman para estudiar textos poéticos. Como se sabe, F. Dostoevskij fue el creador del discurso dialógico en la literatura rusa y, si aplicamos el análisis de Baxtin a la novela Niebla de Unamuno, podemos encontrar que el dialogismo, junto con la palabra ajena, es una de las técnicas narrativas que utiliza Unamuno en esta novela.

Palabras clave: Unamuno, Dostoevskij, Baxtín, dialogismo, Lotman, "palabra ajena”.

\section{Dialogism and "alien word" in the novel of Unamuno "Mist"}

\begin{abstract}
The article evaluates narrative techniques used by Unamuno in the novel "Mist". For theoretical basement we use the analytic methods of M. Bakhtin (which investigated texts of F. Dostoyevsky) and Yuri Mikhailovich Lotman. It's well known that the dialogism in russian literature first appeared in the texts of F. Dostoyevsky. Like Dostoyevsky, Unamuno used the dialogism and "alien word" in his famous text "Mist".
\end{abstract}

Key words: Unamuno, Dostoyevsky, Bakhtin, Lotman, dialogism, "alien word". 


\section{Наивысшая освободительная сила искусства в том, что она заставляет человека усомниться в своем сущеетвовании. Виктор Готи}

\section{Введение}

В настоящей статье на примере романа Унамуно «Туман» рассмотрены феномены диалогичности и «чужого слова» как инструменты для самопознания личности автора.

\section{1. Диалогичность: ее суть}

В Антологии Теории и Критики ${ }^{1}$ термин «интертекстуальность» определяется следующим образом: «отношение текста к предыдущим ему словам, идеям, коннотациям, кодам, согласованиям, случайным соответствиям и другим текстам. Каждый текст является интертекстом, который -сознательно или бессознательно- заимствует часть из обширного архива культуры прошлого».

Термин «интертекстуальность» сформировался в XX веке, стимулом этому послужили две работы русского ученого М. Бахтина (БАХТИН 1963,1965). В них впервые высказано мнение о том, что природа всякого дискурса диалогична. В памяти реципиента текста хранится множество текстов, созданных в прошлом. Новый текст автора (который, со своей стороны, является и читателем) создается на основе уже существующих, а также на относительно недавно созданных текстах. Новый текст вступает в диалогическую взаимосвязь с предыдущими текстами таким образом, что в дискурсе различается не только текст адресанта, но и совокупность голосов:

...Самосознание героя у Достоевского сплошь диалогизовано: в каждом своем моменте оно повернуто вовне, напряженно обращается к себе, к другому, к третьему. Вне этой живой обращенности к себе самому и к другим его нет и для себя самого. В этом смысле можно сказать, что человек у Достоевского есть субъект обращения. О нем нельзя говорить, - можно лишь обращаться к нему. ..Нет, к нему можно подойти и его можно раскрыть -точнее, заставить его самого раскрытьсялишь путем общения с ним, диалогически. И изобразить внутреннего человека, как его понимал Достоевский, можно лишь изображая общение его с другими. Только в общении, во взаимодействии человека с человеком раскрывается и "человек в человеке", как для других, так и для себя самого... Быть - значит общаться диалогически. Когда диалог кончается - все кончается. Поэтому диалог в сущности не может и не должен кончаться. В плане своего религиозно-утопического мировоззрения Достоевский переносит диалог в вечность, мысля его как вечное со-радование, со-любование, со-гласие. В плане романа это дано как незавершимость диалога, а первоначально - как дурная бесконечность его. Все в романах Достоевского сходится к диалогу, к диалогическому противостоянию, как к своему центру. Все -

\footnotetext{
1 "Introduction to Theory and Criticism", The Norton Anthology of Theory and Criticism, 21.
} 
средство, диалог - цель. Один голос ничего не кончает и ничего не разрешает. Два голоса - minimum жизни, minimum бытия. (БАХТИН 1963: 150)

По мнению М. Бахтина, в романах Достоевского создана новая модель героя, который не является выразителем позиции автора, вместо этого имеет свою, отличающуюся позицию. Замысел автора о герое является замыслом о слове, из чего следует, что слово автора о герое является словом о слове. Замысел ориентируется на герое, как на слове, и поэтому обращен к нему диалогически:

В замысле Достоевского герой - носитель полноценного слова, а не немой, безгласный предмет авторского слова. Замысел автора о герое - замысел о слове. Поэтому и слово автора о герое - слово о слове. Оно ориентировано на героя, как на слово, и потому диалогически обращено к нему. Автор говорит всей конструкцией своего романа не о герое, а с героем. Да иначе и быть не может: только диалогическая, соучастная установка принимает чужое слово всерьез и способна подойти к нему, как к смысловой позиции, как к другой точке зрения. Только при внутренней диалогической установке мое слово находится в теснейшей связи с чужим словом, но в то же время не сливается с ним, не поглощает его и не растворяет в себе его значимости, т. е. сохраняет полностью его самостоятельность как слова. Сохранить же дистанцию при напряженной смысловой связи - дело далеко не легкое. Но дистанция входит в замысел автора, ибо только она обеспечивает чистый объективизм изображения героя.( БАХТИН 1963: 39).

\section{2. «Чужое слово»: его суть}

\section{Ю. Лотман полагал:}

Поэтический текст живет в пересекающемся поле многих семантических систем, многих “языков”, причем информация о языке, на котором ведется сообщение, реконструкция этого языка слушателем, “обучение” слушателя новому для него типу художественного моделирования часто составляют основную информацию текста (ЛОТМАН 1996: 109-116).

Выражаясь иными словами и основываясь на теории интертекстуальности, каждый текст не может быть структурно «ожидаемым», что будет обусловлено связью с текстами, написанными хронологически раньше него. Упомянутая связь будет не только ассоциативной, но гораздо более близкой - в новом тексте можно встретить фрагменты, цитаты, введения и другие части предыдущих текстов. Следовательно, значение «языка» поэтического текста может быть расширено и будет содержать в себе не язык, на котором написан стих (в узком понятии), но и другие языки, влияние которых испытывает данный текст.

Из вышесказанного можно заключить, что поэтический текст по своей природе полифонический, в нем различается не один (более редко), а несколько (более часто) голосов. Это возвращает нас к теории М. Бахтина, согласно которой, автор и герой находятся в диалогических отношениях. 
Мы не согласны с позицией Ю. Лотмана о том, что поэзия по своей структуре -как определенный тип речи- является, с лингвистической точки зрения, монологичной. Особенно не так это в случае романтической поэзии, в которой всегда налицо конфликт между автором и героем, или автором и его «я», а также в случаях удвоения личности автора, аутодиалога и др. Расхождения или конфликт внутри позиции автора является не чем иным, как диалогом, учитывая то обстоятельство, что автор романтического текста лишен каноничности и догматичности и не вооружает героя собственной позицией, а беседует с ним и представляет его, как равного.

Если сформировать мысль еще глубже, можно сказать, что у полифонического текста столько авторов, сколько отличающихся диалогичных идей он содержит. Количество же таких авторов может быть минимум три: автор, его удвоенная личность и герой. Если в ходе сюжета меняется направление идеи героя, то есть если он тоже удвоился, тогда авторов будет не три, а четыре, и так до того, пока произведение не закончится (то есть пока оно не станет частью нового текста). Следовательно, чем полифоничнее текст, тем больше слоев идей он содержит, что увеличивает его художественную ценность.

Следует отметить, что в том же тексте Ю. Лотман сам отказался от своего суждения и указал, что «поэтический (художественный) текст в принципе полифоничен» (ЛОТМАН 1996: 109-116).

Понятие «чужого слова» должно быть отделено от смежного с ним понятия «влияния», так как в определенном смысле указанные два понятия могут пересекаться ${ }^{2}$. Выражаясь точнее, «влияние» производится стилем, темой или идеей, тогда как «чужое слово» создается «текстом» или «словом», которые вставленны в данный текст. Вставка может быть прямой (в виде цитаты), или же во время диалога. Именно поэтому диалог и приобретает особое значение для художественного выражения идеи: он является носителем связи с другими текстами (элементом интертекстуальности) ${ }^{3}$. Таким образом, «влияние» и «чужое слово» могут быть звеньями цепочки интертекстуальности.

Из вышесказанного возникает вопрос: какие еще звенья могут быть в упомянутой цепочке? На два из них мы уже указали. Упомянули и третьее - диалог. К перечисленным можно добавить и четвертое - «время», которое присутствует или отсутствует в диалоге. При внимательном рассмотрении диалога между автором и героем можно обнаружить, что «время» иногда фиксируется, а в других случаях - нет.

Фиксирование или стирание временного пространства утончает структуру художественного текста и придает ему завершенный вид. Если учитывать

\footnotetext{
2 К примеру, на поэзию Ф. Тютчева и Г.А.Беккера несомненно влияние Г.Гейне, тогда как «чужим словом» в тексте Ф. Тютчева может быть «слово» А. С.Пушкина. Подробнее см.: Р. Лейбов, А. Осповат. Чужое слово y Тютчева. < http://www.utoronto.ca/tsq/15/ospovat15.shtml>

3 В XX главе «Тумана» явный пример интертекстуальности. Отрывок беседы Аугусто и Виктора (- Как сумасшедший. Вчера нанес визит родственникам Эухении и увидел ее.../ - И она на тебя посмотрела? Не так ли? И ты поверил в Бога?/ - Нет, она не посмотрела - она окутала меня своим взглядом; и не то чтобы я поверил в Бога, но поверил, что я и есть Бог.) однозначно указывает на XVII стихотворение Г.А.Беккера (Сегодня мне улыбаются земля и небеса/Сегодня в душе моей солнце, сегодня ушла тревога/Сегодня я ее видел...Она мне взглянула в глаза/Сегодня я верю в бога).
} 
основные характеристики теории интертекстуальности, согласно которой каждый новый текст дериват предыдущего, а новый автор - продолжение былого, то данный текст и автор то фиксируются, то стираются, иными словами - их стирает «время», исходя из намеченной цели произведения.

Еще одним звеном в цепочке является понятие «идеи». Следует отметить, что она отличается от других звеньев высоким индексом мутации. Более того, в определенном контексте, в следствие новой мутации «новая» идея может целиком потерять связь со «старой». Данный художественный прием дает возможность автору представить старую идею в новом плане. Чем глубже идея, тем богаче будет выражен ее смысл и тем полифоничнее будет текст.

Говоря о глубине идеи мы имеем в виду ее многослойность. Каждая идея может нести поверхностное значение, которое в глубине будет содержать дополнительную информацию. Например, традиционное понятие любви может быть трансформировано в понятие влечения поездом или дождем. Однозначно, что поезд или дождь не являются контакными означаемыми, однако с их помощью автор может рассматривать такие идеи, как, к примеру, любовь.

\section{3. Философские воззрения Унамуно}

Вкратце ознакомимся с теми философскими направлениями, под влиянием которых находился автор «Тумана».

В первую очередь следует упомянуть философско-религиозное учение Краусизма, от которого Унамуно позаимствовал такие идеи, как бытие, гуманизм, всеобщее предназначение и самопознание.

В литературной критике широко распространено также мнение о влиянии Серена Обю Кьеркегора на эволюцию мысли испанского философа (LOMBARDI (1936); EVANS (2005); COLLADO (1962), ROBERTS (1986); NOZICK (1971), FASEL (1995); OSCAR (1955); BLANCO AGUINAGA (1964); WEBBER (1964); EVANS (2006)), касающееся таких идей, как нравственно-религиозныий индивидуализм, возникший на базе иррационального, и бессмертие. Более того, в одной статье рассматривается влияние работы Кьеркегора на роман «Туман» (ARDILA 2008).

\section{4. Диалог как инструмент перестройки художественного текста}

Испанский философ и писатель Мигель де Унамуно использовал диалог как инструмент трансформации жанра, в частности романа. В изданной в 1914 году новелле «Туман» ${ }^{4}$ автор не скрывает желания создать новый, отличающийся от романа, жанр и даже придумывает ему название - «нивола» 5 :

\footnotetext{
${ }^{4} \mathrm{C}$ русским переводом текста можно ознакомиться в интернете:

http://www.gramotey.com/?open file $=1269098331$ \#TOC id1182556

5 В русском переводе - «руман» вместо «романа» (novela vs. nivola).
} 
- Однажды я слышал рассказ Мануэля Мачадо, поэта и брата Антонио Мачадо, о том, как он пришел к дону Эдуардо Бено с сонетом, написанным александрийским стихом или еще каким-то еретическим образом. Прочел он сонет, а дон Эдуардо говорит ему: «Но ведь это не сонет!» — «Да, сеньор, ответил ему Мачадо, - это не сонет, а сонит». Поскольку мой роман не будет настоящим романом, то он будет... как я сказал?.. рамон, нет-нет, руман, да, руман! И никто не посмеет сказать, будто мой роман ломает правила своего жанра... Я изобретаю новый жанр - а чтобы изобрести новый жанр, надо просто придумать новое название, — и даю ему любые правила, какие мне угодно. И побольше диалога.

Интересно, что Унамуно с самого начала указывает на роль диалога. Более того, он говорит о необходимости диалога гораздо раньше, чем определяет название нового жанра: «Будет в основном диалог, главным образом, диалог. Важно, чтобы персонажи разговаривали, разговаривали много. Хотя бы ничего и не сообщали».

Естественно, что подобное заявление должно быть подкреплено авторской задумкой, особым художественным приемом, который несет определенную функцию в тексте. Целью настоящей статьи и является определение таковой.

\section{5. Основные понятия текста: знание, любовь, бытие}

Вернемся к тексту. Главный герой -безутешный сирота Аугусто Перес- старается познать самого себя и найти свое место в окружающем его мире. В круг размышлений героя входит и понятие любви - одна из актуальных тем Унамуно, рассматриваемая автором и в других романах. Можно сказать, что осью повествования являются личные увлечения героев (не только главного), на это настроен художественный замысел писателя , вопрос самопознания. Реализуется же замысел с помощью диалога.

Для детального представления главного замысла писателя предлагаем следующую схему:

$$
\begin{aligned}
& \text { любовь - ось } \\
& \text { самопознание - замысел } \\
& \text { диалог - инструмент }
\end{aligned}
$$

Любовь является осью произведения, на это указывает его начало: в первой же главе Аугусто встречается с Эухенией, во второй главе он принимает решение бороться за нее, а в третьей уже начинает вырисовываться замысел автора, когда Виктор говорит ему:

- Очень просто, ты любишь ab origine, с самого рождения. У тебя врожденная влюбленность. - Да, любовь рождается вместе с нами. - Я сказал не «любовь», а «влюбленность». 
Унамуно разграничивает два понятия - «любовь» и «влюбленность». И вся следующая глава посвящается размышлениям о природе любви. При этом автор обобщает и углубляет предмет размышления - он старается провести хронологическую цепочку от любви к знанию и заключает: «Сначала любовь, знание - потом».

Писатель завершает поток мыслей определением того, что больше всего его интересует: на вопрос что такое «знание», он отвечает: «Знание - это град камней» и тут же опровергает самого себя: «Нет. Это туман, туман!».

Этот отрывок важен для всего романа. Если начать его изучение с конца, то мы увидим, что конечное определение «знания» совпадает с названием романа. Однозначно, что это не случайно. Понятие туман можно рассматривать с различных точек зрения: им обозначаются практически все идеи, которые остаются нерешенными для автора. В частности: знание, любовь, бытие. Неудивительно, что эти три упомянутые понятия изучаются автором не только в рассматриваемом нами романе «Туман», но и в других романах («Абель Санчес», «Любовь и педагогика» и др.), и являются основной цепочкой размышления многих эссе Унамуно.

Следовательно, многие тексты автора можно представить одним текстом, или текстами, которые (в процессе письма) порождают друг друга, что-то подобное «авто-интертекстуальности». Примером того может послужить указание некоторых ученых на одну тему в разных романах писателя.(CALMES 2007)

Интересным представляется расшифровка высказывания: «Знание - это град камней». По нашему мнению, Унамуно сравнил знание с камнем, исходя из свойства последнего: не его тяжести, а его твердости, так как лишь конкретное может явиться опорой точности. Свойство же тяжести может быть переходящим, невечным.

На этой главе можно было закончить роман. Казалось, замысел автора уже не только вырисовывается, но и нагляден. Однако в следующей главе Унамуно употребляет свой любимый прием - самоопровержение-, и после вынесения почти всех определений (так как он еще не определил «бытие») он вновь погружает героя в туман.

Более того, автор переносит героя в далекое прошлое (в детство) и показывает его полное неумение владеть жизненными ситуациями: «Будь мама жива, она нашла бы выход, - сказал себе Аугусто, — в конце концов, это не труднее, чем квадратное уравнение, и, по существу, это не более чем квадратное уравнение». И резюмирует: «Все мы подкидыши, Доминго».

В этом выражении можно рассмотреть начало клубка новой мысли попытку определить бытие. Слово «подкидыш» коннотируется со словом «туман», дескать жизнь - это туман, а мы - подкидыши. Вот тут-то и происходит сцепление предыдущих понятий с последним - с бытием, и автор заканчивает главу словами: «унылыми были и сны в ту ночь».

М. Бахтин в цитируемой нами работе о поэтике Достоевского указывал на вхождение идеи в состав диалог по тому же принципу диалогичности, то есть на то, что рассмотрение идеи также диалогизировано: 
Идея в узком смысле, т. е. воззрения героя как идеолога входят в диалог на основе того же принципа. Идеологические воззрения, как мы видели, также внутренне диалогизированы, а во внешнем диалоге они всегда сочетаются с внутренними репликами другого, даже там, где принимают законченную, внешне монологическую форму выражения.

То же самое можно сказать и в случае с «Туманом». Изначально размышление над идеей появляется в диалоге, но формируется в автодиалоге, то есть тогда, когда Аугусто остается один.

К примеру, можем обратиться к уже цитируемой нами третьей главе, когда Виктор указывает Аугусто, что у последнего врожденная влюбленность. В пятой же главе Аугусто приступает к автодиалогу со словами: «Но, может, Виктор прав? Может, я влюблен ab initio?».

Бахтин разграничивает платонический диалог (по форме своей не «сплошь монологизированный, педагогический диалог», но все-таки ориентированный на идею, которая мыслится не как событие, а как бытие) и заключает: «диалог Достоевского вовсе не чисто познавательный, философский диалог». Между тем как у Унамуно диалог глубоко философского характера.

В конце этой части статьи настало время рассмотреть два определения, употребляемые Унамуно на протяжении всего текста - туман и сон. По нашему мнению, оба несут одну и ту же функцию: указывают на нереальность бытия, иными словами, оба доказывают нереальность реальности, или реальность нереальности (словами Унамуно). Жизнь может быть сном или туманом, в котором невозможно что-нибудь рассмотреть, иными словами, жизни не существует. Именно такой представляется нам философия жизни автора.

\section{6. Основная функция диалога}

Унамуно не удовлетворился новым художественным приемом - диалогом, развил его до автодиалога и, не останавливаясь на этом, ввел нового героя Орфея, который стал новой причиной инициации диалога. Диалог с собакой, то есть с существом, которое само не может участвовать в беседе, новый и особенный инструмент многоголосия персонажа.

С одной стороны, может показаться, что вводить собаку было незачем Аугусто беседовал с самим собой, а также с Виктором, который, в отличие от собаки, совершенно определенно мог высказать позицию автора. Однако Унамуно не удовлетворился говорливыми персонажами и ввел немого. И превратил немого в говоруна в конце романа. Чем это может быть объяснено?

По нашему мнению, новая задумка Унамуно может иметь несколько причин. Можно заключить, что немой инициатор диалога является новым видом автодиалога. Если вначале Унамуно говорил устами Аугусто, то теперь сам Аугусто говорит устами Орфея. Или: Унамуно говорит устами Орфея, проводя мысль через еще один, дополнительный, медиум - уста Аугусто. Целью настоящего может быть желание Унамуно еще больше рафинировать высказываемую мысль. 
С другой стороны, Орфей может являться символом слабости и неразвитости мысли - интересно, что два основных носителя идей автора -Аугусто и Орфей- умирают один за другим.

В «Надгробном слове вместо эпилога» Унамуно пишет:

По обычаю, в конце романа, после того как герой, или протагонист, умирает или женится, полагается рассказать о судьбе остальных персонажей. Мы не собираемся следовать этому обычаю и не станем сообщать, что случилось потом с Эухенией и Маурисио, с Росарио, с Лидувиной и Доминго, с доном Фермином и доньей Эрмелиндой, с Виктором и его супругой и со всеми другими людьми, которые предстали перед нами вместе с Аугусто... За одним исключением- и оно коснется того, кто глубже и искренней всех горевал о смерти Аугусто, - речь идет о его собаке Opфee.

Интересно - почему? Почему лишь Орфей, Орфей, который играл второстепенную по сравнению с Аугусто роль? Несомненно, что конец романа -слова Доминго («А еще говорят, что горе не убивает!»)- является приемом самоопровержения автора: собака, дескать, умерла от тоски по хозяину, а вовсе не от бытия в небытии.

Именно идея тумана/небытия кажется нам основной в романе, что может быть подкреплено еще одним обстоятельством или героем: Доном Авито Карраскалем, который показан и в «Тумане» и в «Любви и педагогике». Унамуно хочет подчеркнуть идею небытия множественным бытием.

\section{7. Основная функция «чужого слова»}

Являясь одним из элементов интертекстуальности, «чужое слово» активно используется автором для обоснования собственных идей. В частности, мы уже цитировали отрывок из XX главы «Тумана», в котором Унамуно, желая доказать свою веру в Бога, цитирует Беккера (см.ссылку 4). Ту же цель преследует и беседа с Доном Авито Карраскалем, когда последний объясняет Аугусто причину своего прихода в церковь:

...С тех пор как мой бедный Аполодоро, моя жертва, - при этих словах в голосе его послышались .рыдания, - умер, точнее, покончил с собою, с тех пор для меня нет настоящего, нет ничего нужного для меня ни в науке, ни в действительности. Я могу жить только воспоминанием или надеждой. Вот я и пришел сюда, к очагу всех иллюзий и всех разочарований, в Церковь!

Следовательно, по мнению автора, в церковь людей толкает или иллюзия, или разочарование. Церковь ему представляется определенным подобием солидарности и общности:

- Не знаю, верую я или нет; знаю лишь, что молюсь. И даже толком не знаю, о чем молюсь. Нас здесь несколько человек, но вечерами мы собираемся в этом 
храме помолиться. Я незнаком с ними, а они - со мною, но мы чувствуем некую солидарность, духовную общность.

\section{8. Позиция автора и позиция героя}

Изучая романы Достоевского, М. Бахтин указывал на одноврменное существование двух позиции - автора и героя. По мнению ученого, независимая позиция героя не означает отсутствия позиции автора. Более того, мы не должны рассматривать романы Достоевского, как лишенные позиции автора. Наоборот, позиция автора не только вырисовывается, но выражена достаточно четко. Отличает его от монологического романа лишь то, что герой не является объектом сознания автора, а приобретает равные с ним права:

Самосознание как художественная доминанта в построении героя уже само по себе достаточно, чтобы разложить монологическое единство художественного мира, но при условии, что герой, как самосознание, действительно изображается, а не выражается, т. е. не сливается с автором, не становится рупором для его голоса, при том условии, следовательно, что акценты самосознания героя действительно объективированы и что в самом произведении дана дистанция между героем и автором. Если же пуповина, соединяющая героя с его творцом, не обрезана, то перед нами не произведение, а личный документ. Произведения Достоевского в этом смысле глубоко объективны, и потому самосознание героя, став доминантой, разлагает монологическое единство произведения (не нарушая, конечно, художественного единства нового, не монологического типа). Герой становится относительно свободным и самостоятельным, ибо все то, что делало его в авторском замысле определенным, так сказать, приговоренным, что квалифицировало его раз и навсегда как законченный образ действительности, - теперь все это функционирует уже не как завершающая его форма, а как материал его самосознания. (БАХТИН 1963: 37)

Интересно, как распределил Унамуно отмеченные выше позиции?

Подобно Достоевскому, Унамуно тоже разграничивает две позиции. Цель, которую он при этом преследует, сводится к тому же, к чему и использование диалога - к смопознанию. Обратимся к тексту.

XXXI глава целиком посвящается идее самопознания и является своеобразным заключением всего романа. Она состоит из диалога автора с героем.

Аугусто Перес приезжает в Саламанку, чтобы встретиться с Унамуно. Приняв решение покончить с собой, он решил спросить совет у ученого, с текстами которого он был знаком.

Унамуно раскрывает Аугусто секрет его существования, который заключается в том, что тот не существует:

...-Дело в том, что ты не можешь покончить с собой, ибо не живешь - ты не живой и не мертвый, ибо не существуешь. - Как это я не существую? - воскликнул он. - Потому что ты выдуманное существо, бедный Аугусто. Ты только плод моей фантазии и фантазии читателей моего повествования о твоих вымышленных 
приключениях и злосчастьях. Ты всего лишь герой романа или румана — называй мою книгу, как тебе угодно. Ну вот, теперь ты знаешь свой секрет.

И тут же Унамуно указывает на роль диалога в своих текстах: «И когда мне не с кем поспорить, я придумываю себе оппонента. Мои монологи - всегда диалоги».

Следовательно, диалог является инструментом самопознания для автора. Именно в диалоге раскрываются все возможности мышления - высказывая и аргументируя мысль, доводя ее до кондиции и формируя, Унамуно внезапно опровергает ее, преследуя единственную цель - доказать обратное, опровергнуть достигнутое. Это и демонстрируют слова Аугусто:

Вы тоже умрете! Тот, кто выдумывает, выдуман сам, а кто выдуман, тот умрет. Вы умрете, дон Мигель! Умрете вы и все, кто обо мне думает. Раз так - умрете все!

Р. Барт в работе «Смерть автора» БАРТ (1994).указывает на уменьшение роли автора в книге:

Удаление Автора (вслед за Брехтом здесь можно говорить о настоящем “очуждении" - Автор делается меньше ростом, как фигурка в самой глубине литературной “сцены”) - это не просто исторический факт или эффект письма: им до основания преображается весь современный текст, или, что то же самое, ныне текст создается и читается таким образом, что автор на всех его уровнях устраняется.

Именно в этом и заключалась цель Унамуно - в самоустранении. Таким образом, автор постарался освободиться от субъективности в мышлении, чтобы направить мысль на объективные рельсы. Диалог, при котором вырисовывается отличающаяся, немонологическая позиция, помогает автору посмотреть на собственные суждения со стороны, рассмотреть отличающиеся точки зрения и постараться сформировать мысль.

Несмотря на это, ни одна рассматриваемая мысль до конца так и не сформирована, и, размышляя над ними, всегда остается чувство неуверенности, в первую очередь, выраженная самим автором, что допустимо существование другой мысли и другого бытия:

Ибо я жажду — о мои читатели! - быть собой и вами одновременно, быть чемто и в то же время быть каждым из вас. Ведь если б я был только самим собой, Мигелем де Унамуно, каждый из вас, читающих мои книги, меня бы не читал. Ведь если я не скажу вам нечто уже записанное в глубине души вашей, хотя сами вы этого и не знаете, вряд ли вы станете меня читать. Итак, я желаю придать форму темным и смутным мыслям ваших душ. И если иногда вы раздражаетесь против сказанного мною и негодуете - значит, я нащупал нечто глубоко спрятанное в изгибах и складках вашего сознания, что вас мучает.

\section{9. Заключение}

Унамуно использовал диалог для перестройки жанра. Выражая мысль и формируя ее, писатель опровергает ее, чтобы рассмотреть с другого конца. 
Целью подобного выражения несомненно является желание автора увидеть реальность в разных планах, рассмотреть разные точки зрения и высказать завершенную, сформированную мысль; диалог является лишь инструментом для достижения основной цели автора - самопознания.

Унамуно отказался от монолога, как от формы самовыражения, намереваясь выразить разные точки зрения по поводу одной идеи; в отличие от романа Достоевского, диалог Унамуно носит философский характер.

Тут следует принять во внимание тот факт, что автор сам был философом, и комплексное, разностороннее мышление присуще его профессиональному формированию.

Можно допустить, что целью Достоевского было лишь художественное выражение, тогда как Унамуно преследовал цель философского мышления, диалога; основной функцией диалога может служить создание нового вида автодиалога (когда диалог ведет немой герой, в рассмотренном нами случае: Орфей), или же диалог может быть презентацией бытия в небытие.

Обе цели служат самопознанию; также как и в романах Достоевского, в текстах Унамуно резко разграничены позиции автора и героя. Цель, к достижению которой стремится Унамуно, заключается в самоустранении, в освобождении от субъективности, в желании найти окончательный ответ; «чужое слово», наравне с диалогом, является одним из составляющих элементов интертекстуальности. Унамуно вводит его с той же целью, что и диалог взглянуть на поставленный вопрос со стороны, что является объязательным условием для самопознания.

\section{Библиография}

БАРТ, Р. (1994): Избранные работы: Семиотика. Поэтика, Москва, с. 384-391.

БАХТИН, М.М. (1963,1974, 1979): Проблемы поэтики Достоевского, Москва.

БАХТИН, М.М. (1965,1990): Творчество Франсуа Рабле и народная культура средневековья и Ренессанса, Москва.

ЛОТМАН, Ю.М. (1996): «Чужое слово в поэтическом тексте» в $O$ поэтах и поэзии. Анализ поэтического текста, Санкт-Петербург, с. 109-116.

AGUNIAGA, B. (1964): "Unamuno's Niebla: Existence and the Game of Fiction”, MLN, Vol. 79, No. 2, Spanish Issue, pp. 188-205

AGUNIAGA, B. (1956): "La madre, su regazo y el "sueño de dormir" en la obra de Unamuno", Cuadernos de la Cátedra de Miguel de Unamuno, Número: VII, 1956 Página(s): $69-84$

ARDILA, J.A.G. (2008): "Nueva lectura de Niebla: Kierkegaard y el amor", Revista de Literatura, enero-junio, vol. LXX, n.o 139, pp. 85-118.

CALMES, V. (2007): "La esposa/madre: Matrimonio como salvación en Niebla de Unamuno", the 60th Annual Kentucky Foreign Language Conference, April 19-21.

COLLADO, J. (1962): Kierkegaard y Unamuno. La existencia religiosa, Gredos, Barcelona. EVANS, J. E. (2005): "Passion, Paradox, and Indirect Communication. The Influence of 'Postscript' on Miguel de Unamuno", en Kierkegaard Studies. Yearbook 2005 (Cappelørn,Niels Jørgen, Hermann Deuser \& K. Brian Söderquist, eds.), Berlin/New York, pp. 137-152; 
EVANS, J. E. (2006): "Kierkegaard,Unamuno, and Don Quijote as the Knight of Faith", Symposium, 60, pp.3-16.

FASEL, O. A. (1955): “Observations on Unamuno and Kierkegaard”, Hispania, Vol. 38, No. 4, pp. 443-450;

LOMBARDI, F. (1936): Kierkegaard, Firenze: La Nuova Italia

NOZICK, M. (1971): Miguel de Unamuno, Twayne, New York.

ROBERTS, G. (1986): Unamuno: afinidades y coincidencias kierkegaardianas, Society of Spanish and Spanish-American Studies, Boulder.

WEBER, R. H. (1964): "Kierkegaard and the Elaboration of Unamuno's Niebla”, Hispanic Review, Vol. 32, No. 2, pp. 118-134. 